\title{
Formulation of Higher Education Institutional Strategy Using Operational Research Approaches
}

\author{
Ashraf Labib*, Charlotte Gladstone-Millar, Richard Tonge, David Smith, Martin Read \\ Portsmouth Business School, University Of Portsmouth, United Kingdom
}

\begin{abstract}
*Corresponding author
Abstract:

In this paper a framework is proposed for the formulation of an HE institutional strategy. The proposed hybrid model is based on two operational research (OR) methodologies named multiple criteria decision making (MCDM) and resource allocation. The Analytic Hierarchy Process (AHP) is a technique linked to MCDM that helps to address issues related to formulation of a model which represents different factors and alternatives, assess their priorities, and provide a decisionmaking mechanism. Then a resource allocation approach called the 'Knapsack method' is used to incorporate derived global priorities of strategic options from the AHP technique in order to optimise different types of resources. The proposed model is dynamic in that it adapts to changing economic and environmental conditions and hence has the capability to provide 'what-if' analysis. The framework is applied in the context of strategic decision making for a business school and involves key stakeholders who have responsibilities for strategic functions within the HEI and the school.
\end{abstract}

\section{INTRODUCTION}

Complex situations such as environmental changes and their impact upon higher education institutions are major challenges that require innovative and efficient approaches to model and provide decision support. In this paper we use operational research (OR) techniques in the field of Higher Education Institution (HEI) strategic management.

In many decision scenarios there are multiple goals which need to be achieved and which involve a variety of stakeholders who have different and sometimes conflicting objectives. Therefore there is a need to evaluate decisions based on multiple criteria.

In this paper we extend previous work (Gladstone-Millar et al, 2012) where we proposed an OR methodology named 'multiple criteria decision making' (MCDM) using a technique linked to MCDM called the Analytic Hierarchy Process (AHP) into a hybrid model where we link AHP to a resource allocation method. In the previous work the AHP addresses issues related to the formulation of a model representing the different factors and alternatives, assessing their priorities, and providing a decision-making mechanism. In this current work the resource allocation approach called the 'Knap-sack method' helps to optimally allocate resources. We demonstrate this approach using an example that shows the underlying theory of the OR approach in order to enrich management understanding and, as a whole, offer a 'tool box' of OR approaches for HE management.

The proposed model is dynamic in that it adapts to changing economic and environmental conditions and hence has the capability to provide 'what-if' analysis. 
It is applied in the context of strategic decision making for a business school and involves 'influencing factors' such as economic conditions and the competitive environment. It also involves key stakeholders in the decision making process who have responsibilities for strategic functions within the HEI and the school, namely: academic quality, research, student experiences and innovation. The model also incorporates the different objectives of the key stakeholders. Finally it considers strategic options for investments. Thus we demonstrate a way to apply OR approaches such as MCDM and resource allocation in the context of strategic decision making in HE, taking into account external conditions, that enable us to prioritise key stakeholders, and their objectives. The proposed dynamic model is able to adapt the outcomes in line with the influences of changing prevailing external conditions on stakeholders' priorities.

\section{Challenges for HEIs}

In the early twenty-first century HEIs are performing a variety of roles. They are introducing many more people to degree level study, conducting increasingly applied research, and working with and for businesses, local communities and the public and voluntary sectors. Part of this diverse role is to help all these sectors to prosper and HEIs are expected to engage locally, regionally, nationally and globally. Indeed in many towns and cities the HEI is one of the largest employers and a focal point for the community.

However, HEIs are also experiencing increasing expectations from government and society at large and there is growing competition between individual HEIs and from private providers of degree-level study for students and research funding. To resolve these pressures HEIs need to be ever clearer about their missions and strategies to create the best return on public and private investment in higher education and on the resources available to senior management.

In common with other sectors of society, the pace of change is increasing, meaning that it becomes ever more important for higher education institutions to be able to gather knowledge and respond swiftly to changes in student expectations, employability trends, funding regimes, international border controls, technological developments, and agendas pertinent to local industries and the voluntary sector, to suggest just a few. Strategic planning using OR techniques provides senior managers with a tool that will allow them to model the changing scenarios in order to refine their strategic plans in response to external and internal drivers.

\section{Importance of strategic planning in HEIs}

In 2000 the Higher Education Funding Council for England (HEFCE) produced a guide to strategic planning in higher education for heads and senior managers of institutions and members of their governing bodies (HEFCE, 2000). The guide is not prescriptive but identifies common principles and provides examples of good practice "to help heads of institutions and senior managers to plan more effectively and so stand a better chance of achieving their institutions' strategic goals" (p. 3). One of the key messages in this guide is the importance that should be placed in analysing the institution and its environment in relation to medium and long-term goals in a methodical and systematic way. The HEFCE guidance draws on key literature sources to provide the academic background which has been used extensively to influence the development of strategic planning practices in HEIs. The model they recommend focuses on identifying the institution's long-term direction using a cyclical model with the three phases of planning, documentation and implementation and monitoring to adapt future strategy. They caution against a 
mechanistic approach associated with a detailed timetable for an annual planning cycle which can stifle creative thinking and impede flexibility and opportunism.

Strategic planning involves planning for the organisation as a whole, rather than planning for individual elements such as production, cash flow, or workforce planning. However strategic planning is recommended for semi-autonomous segments of an organisation, such as a business school, to give direction to separate elements including the marketing strategy and human resources strategy.

For a UK business school its vision might be expressed as:

"By [date] the Business School will be recognised nationally and internationally as a leading UK centre for business and management education and research".

To achieve this vision would involve continued excellence in learning and teaching, research and knowledge transfer, meaningful engagement with business and the public and voluntary sectors and the development of a vibrant executive education portfolio. It would also require strategic investment in areas of excellence. Important areas for strategic investment would include engagement with business and the public and voluntary sectors, a focus on students' employability and growth in applied research, academic entrepreneurship and executive education.

Discussions among the senior management could lead to a strategy expressed as:

- To integrate our research, learning and business and community engagement to enhance the student experience and give benefit to the economic, social and environmental well-being of the locality and beyond;

- To ensure that everything we do is sustainable, with high standards of ethics and integrity;

- To develop further strategic alliances with academic, public sector, voluntary and business organisations and seek opportunities for collaboration within the University and with external partners;

- To continue to build a national and international reputation for our achievements.

The business school is then faced with a quandary. How should limited resources be allocated to the strategic aims? Should each one be pursued with equal vigour, or will an emphasis on just one or two enable the business school to realise its vision sooner? These are questions that the OR model described below can make a valuable contribution towards answering.

\section{A BRIEF OVERVIEW OF THE ANALYTIC HIERARCHY PROCESS (AHP)}

The Analytic Hierarchy Process (AHP) is a multi-criteria decision making (MCDM) method that helps the decision-making unit facing a complex problem which has multiple conflicting and subjective criteria, such as location or investment selection, project ranking and so forth (see Kumar and Vaidya (2006) and Omkarprasad and Sushil (2006) for reviews on applications of AHP and see Ishizaka \& Labib (2009) for a review of different methods in calculating priorities). AHP can accommodate the views of a number of decision-makers (actors) and the trade-off of their objectives. This is in line with the requirements of implementing a strategy for collective change as outlined by Jones and Lewis (1991).

The AHP method is designed to solve complex decision-making problems when there are multiple objectives or criteria to consider. This approach has been introduced by Saaty $(1977,1980 \& 1994)$ and requires the decision-maker(s) to provide judgements about the relative importance of each criterion and then specify a preference on each criterion for each decision alternative. 
The first step in the AHP is defining the problem (the goal) to be solved and the decomposition of the problem into a decision hierarchy (Vassoulla et al, 2006). This may take the form illustrated in Figure 1. The next step is to employ a pairwise comparison of the criteria among themselves with respect to the goal, as well as between the alternatives with respect to each criterion in order to establish priorities amongst the elements in the hierarchy. These comparisons are carried out using Saaty's (1980) predefined one-to-nine ratio scale. The following step is to estimate relative weights of the elements in each level of the hierarchical model. The subsequent following step is to compute the value of the global priorities of alternatives (optional choices) and calculate consistency (or inconsistency). Finally, one can perform sensitivity ('what-if') analysis to study the effect of changing weights of criteria on the final choice.

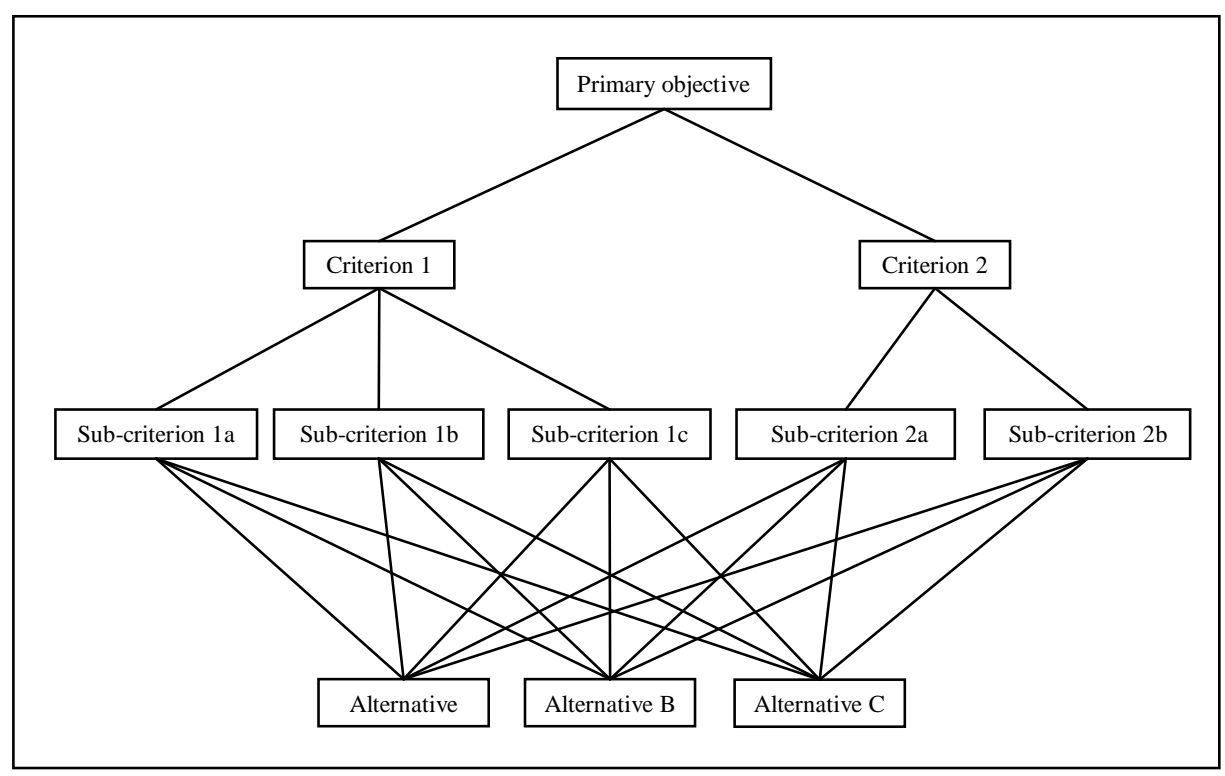

Figure 1. A typical AHP decision hierarchy

Detailed steps in performing AHP as a method for MCDM are as follows:

1. Establish the decision context.

i. Establish aims of the MCDM.

ii. Identify key stakeholders (decision-makers and other key players).

2. Identify objectives and criteria.

i. Identify criteria for assessing the consequences of each option.

ii. Organise the criteria by clustering them under high-level and lower-level objectives in a hierarchy.

3. Identify the options to be appraised (alternatives).

4. 'Scoring'. Assess the expected performance of each option against the criteria.

i. Score the options on the criteria.

ii. Check the consistency of the scores on each criterion.

5. 'Weighting'. Assign weights for each of the criterion to reflect their relative importance to the decision.

6. Combine the weights and scores for each option to derive an overall value. 
i. Calculate overall weighted scores at each level in the hierarchy.

ii. Calculate overall weighted scores.

7. Examine the results.

8. Sensitivity analysis ('what-if' analysis).

i. Conduct a sensitivity analysis: do other preferences or weights affect the overall ordering of the options?

ii. Look at the advantage and disadvantages of selected options, and compare pairs of options.

iii. Repeat the above steps until a 'requisite' model is obtained.

One of the most practical issues in the AHP methodology is that it allows for non-consistent pair-wise comparisons. In practice, particularly with multiple decision-makers, perfect consistency is unusual. The pair-wise comparisons in a judgement matrix are considered to be adequate if the corresponding consistency ratio (CR) is less than $10 \%$ (Saaty, 1980). The consistency measure is a feedback facility to the decision-maker that helps to capture logical and reasonable preferences when making judgements. It is also a validation facility as it supports empirical research conducted by either practitioners or academic researchers to ensure that questionnaires are not poorly answered (Cheng and Li, 2003).

After the alternatives have been compared with each other in terms of each one of the decision criteria and the individual priority vectors have been derived, the priority vectors become the columns of the decision matrix. The weights of importance of the criteria are also determined using pair-wise comparisons. Therefore, given there is one goal, $\mathrm{m}$ criteria and $\mathrm{n}$ alternatives, the decision-maker will create one $(\mathrm{m} \times \mathrm{m})$ matrix for the criteria and $\mathrm{m}(\mathrm{n} \times \mathrm{n})$ matrices for the alternatives. The $(n \times n)$ matrices will contain the results of $n(n-1) / 2$ pair-wise comparisons between the alternatives. Finally, given a decision matrix, the final priorities, denoted by $\mathrm{A}_{\mathrm{AHP}}^{\mathrm{i}}$, of the alternatives in terms of all the criteria combined are determined according to the following formula:

$$
A_{A H P}^{i}=\sum_{j=1}^{n} a_{i j} w_{j}, \text { for } i=1,2,3, \ldots, m .
$$

There are three outputs that can be produced from the AHP process:

- An overall ranking, which helps in understanding how each customer is compared to the others;

- A measure of the overall consistency of the decision-maker's preferences which is a useful feedback for validation of consistency, as explained before. Overall inconsistency of less than $10 \%$ is normally acceptable as a measure of consistent preferences;

- A facility to perform sensitivity analysis ('what-if' analysis) which provides information about the causal relationships between the different factors. This capability can help us to explain and predict the different relationships between criteria and alternatives and is particularly valuable in creating scenarios for movement in relationships (positive or negative). This helps to overcome concerns about customer analysis as static and unhelpful in predicting future resource allocation needs.

\section{STRUCTURE OF THE PROPOSED MODEL}

The AHP is not only a decision support tool for helping decision-makers to select or allocate resources, it also helps to construct a mental model of understanding the nature of the problem (Labib et al, 1997). 
Beginning with the goal to identify investment priorities to achieve strategic objectives in an HEI, a hierarchy is developed (see Figure 2a, and 2b). Moving down from the apex of the hierarchy, the first level of the hierarchy deals with the perceived likely conditions that the HEI may experience. The second level identifies the decision-makers, or the actors, who are related to educational quality, research, students and innovation. In this case the actors are the existing Associate Deans for those functions at a business school which is the subject of this example. The third level is concerned with the objectives of the business school, derived from mapping the objectives of the actors involved. The final tier of the hierarchy considers the alternative strategic options which are to be prioritised. The following discussion deals with the elements of each level in this hierarchy in more detail.

Likely Conditions (Level 1): The first level of the hierarchy contains the status and environmental conditions categorised into four categories which relate to economic conditions and the competitive environment. Economic conditions are classified as either in a recession or a growth condition. The competitive environment (in the context of higher education) is categorised as either a large number of players indicating intense and diverse competition, or a few players indicating that the market still offers limited opportunities (and thus a degree of power) to its incumbent suppliers.

Actors (Level 2): An actor is an individual or a group playing a significant role in responding to forces that shape current events and, therefore, future outcomes (Labib et al, 1997). The main actors in this case study spanning the full range of activities in the business school are the Associate Deans of quality, research, students and innovation (encompassing knowledge transfer and collaborative arrangements). In abbreviated form we use the following terms: ADQ, ADR, ADS and ADI. They are considered to be the most suitable decision-making body within the HEI interested in the prioritisation of the HE strategy at business school level. This is especially true with respect to deriving a league table ranking based on performance indicators, since the majority of indices used are usually the main concerns of those managers. Other actors can be included in the hierarchy according to the structure of each organisation, for example, heads of departments, faculty manager, and so on. Also the students, who some may argue, are the 'customers', and others as the 'product', were not included in the formulation of the strategy, but the model has included actors who have valuable insights into aspects of students perspectives. The aim of this exercise is to present a methodology and a framework rather than a rigid model. This shows that the concept of hierarchies is stable and flexible; stable in that small changes have small effects and flexible in that additions to a well-structured hierarchy do not disrupt the performance (Labib et al, 1997).

Objectives (Level 3): Prioritisation of strategic options will depend on a multitude of objectives, some of which are conflicting, and others are related or complementary. Prioritisation is useful for either a selection decision (choose the best based on the highest ranking score), or as a portfolio resource allocation decision (allocate resources to all options according to the percentage of weights allocated to different alternatives). The objectives of the HEI in this example are to increase: accessibility and flexibility, research ranking, impact of research and knowledge transfer, student satisfaction and HEI reputation, as well as to maximise efficient resource utilisation (defining 'resource' as time, effort, money and people).

Strategic Options (Level 4): Finally, in any hierarchy, one usually considers the specific options that need to be prioritised. 


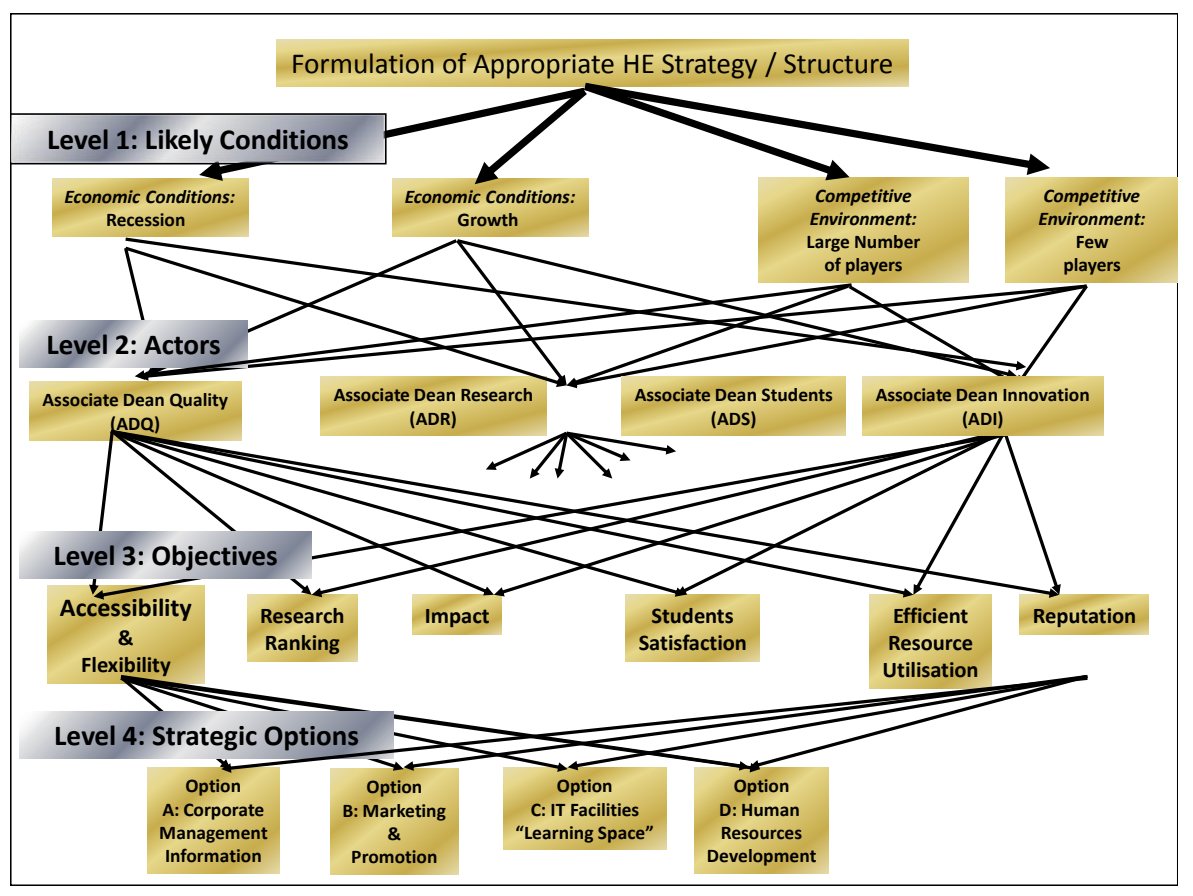

Figure 2a. Proposed hierarchical model based on the AHP

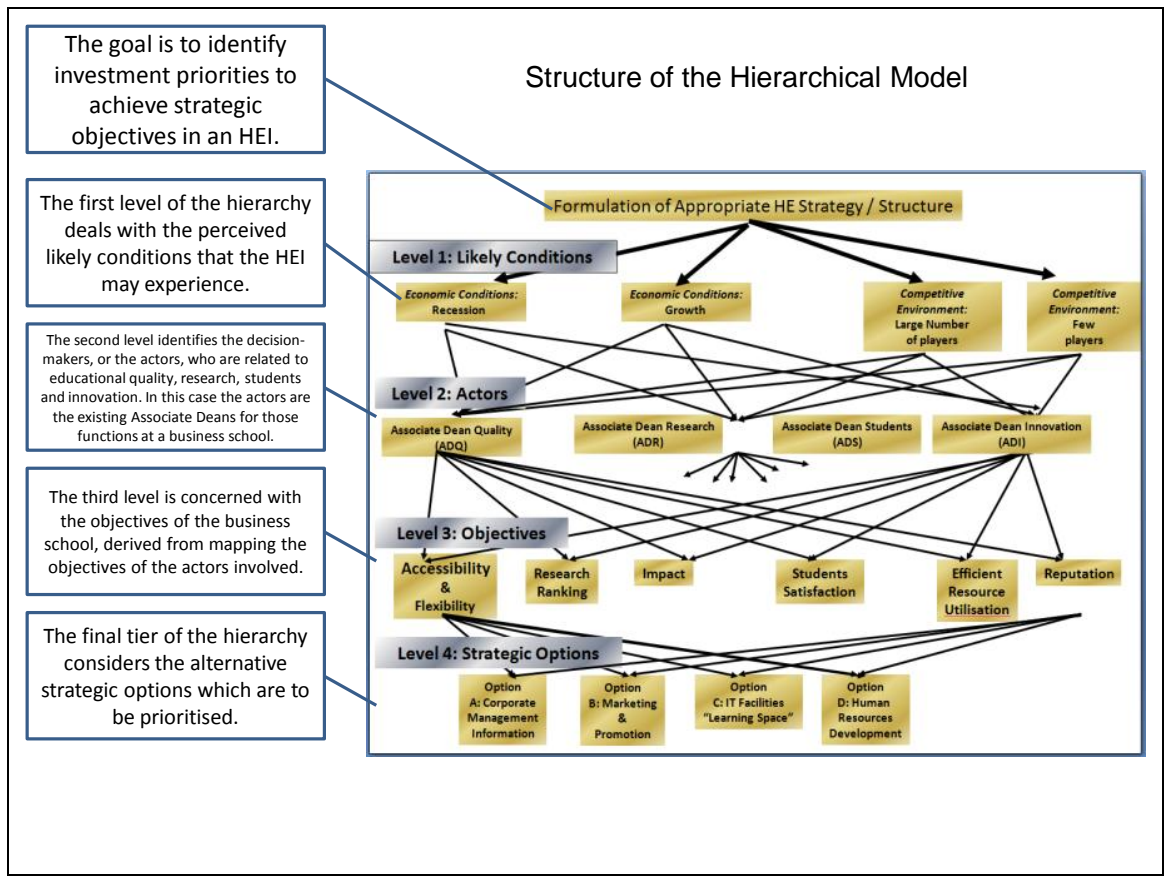

Figure 2b. Proposed hierarchical model based on the AHP with comments on each level 


\section{A DETAILED ANALYSIS USING A CASE STUDY}

The intention here is to present an example of how the proposed model can operate. Assumptions and data used here are illustrative and not intended to be definitive.

Decision applications of the AHP are carried out in two phases: hierarchic design and evaluation. In the previous section, the hierarchic design phase was considered. In this section the second phase, namely the evaluation phase, is considered. The first step is to assess the likelihood of the conditions in relation to the type of industry. Each of the two likely conditions, economic conditions and competitive environment, is divided into two options where the decision-maker needs to score the highest and lowest values with respect to each pair in those four categories.

The next step is to establish priorities amongst the elements in the hierarchy by making pair-wise comparisons of the criteria and later on we apply the same to other levels in the hierarchy until we reach the options level. Given Criterion i and Criterion j, these comparisons are carried out using Saaty's (1980) predefined oneto-nine ratio scale. Figure 3 a shows how such comparisons were made using a 'questionnaire' mode in the Expert Choice software which facilitates the application of AHP.

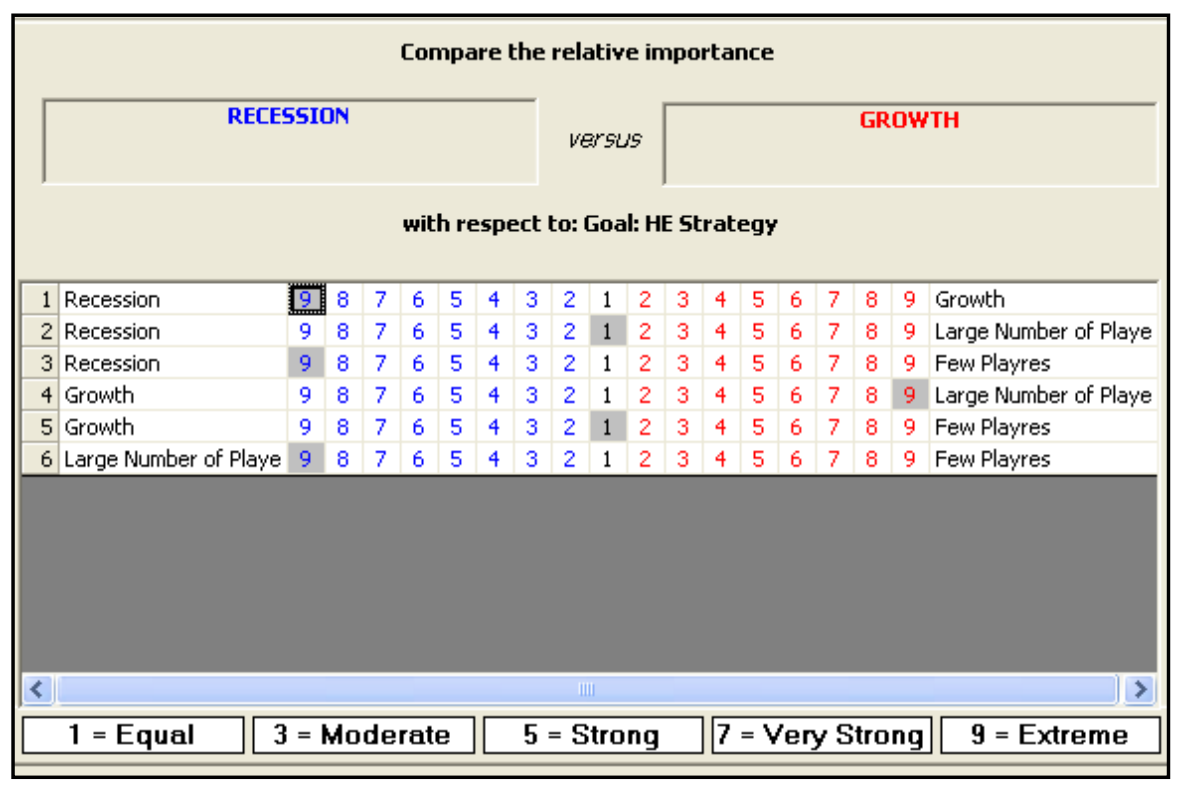

Figure 3a. Example of pair-wise comparison

Each set of questionnaires were printed out and handled to the relevant actor (decision-maker) for making judgements based on pair-wise comparisons as illustrated in Figure $3 b$. 


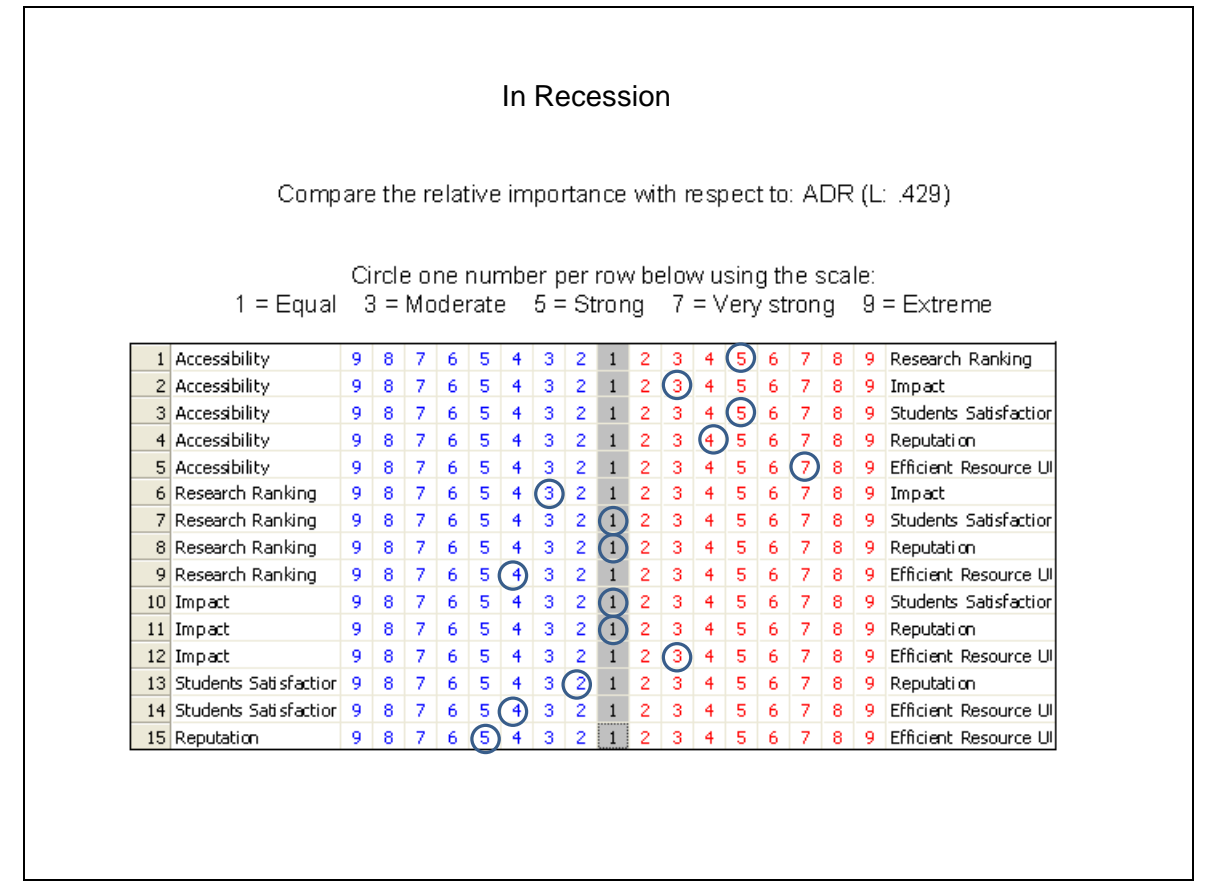

Figure $3 b$. Example of pair-wise comparison completed by respondents

The evaluation is done through a pair-wise comparison by asking: "Which of the following two scenarios is most likely to occur in our current planning cycle?" In this particular case study we have identified the likely conditions to be in a prevailing economic condition which in this case study is a recession, and it can be observed that in row 1, Recession scores the highest value of 9 when compared to Growth. In terms of competitive condition, it is assumed in this case study that competitive intensity is high and hence Large Number of Players scores 9 when compared to Few Players.

The number of pair-wise comparisons is equal to n.(n-1)/2 $=6$, where in our case $n=4$ at that level of the hierarchy. Once the table is completed, the relative likelihood of the 6 scenarios is obtained based on the AHP method explained in the previous section. These priorities are on a ratio scale from 0 to 1 and they all add up to unity as shown in the last column of Table 1.

From Table 1, it is evident that the likely conditions with the highest score of 0.450 in the relative likelihood column are attributed to recession and large number of players.

The computation of the relative likelihood is as follows: the elements of each column are divided by the column sum and then row averages are calculated to obtain local priorities. There are other methods of computing relative priorities as reported in Saaty (1980) and Ishizaka and Labib (2009). 
Table 1. Relative likelihood of scenarios.

\begin{tabular}{lccccc}
\hline $\begin{array}{l}\text { With respect to: } \\
\text { HE Strategy }\end{array}$ & Recession & Growth & $\begin{array}{l}\text { Large } \\
\text { Number } \\
\text { of players }\end{array}$ & $\begin{array}{l}\text { Few } \\
\text { Players }\end{array}$ & $\begin{array}{l}\text { Relative } \\
\text { Likelihood }\end{array}$ \\
\hline Recession & 1 & 9 & 1 & 9 & 0.450 \\
Growth & $1 / 9$ & 1 & $1 / 9$ & 1 & 0.050 \\
$\begin{array}{l}\text { Large Number } \\
\text { of players }\end{array}$ & 1 & 9 & 1 & 9 & 0.450 \\
Few Players & $1 / 9$ & 1 & $1 / 9$ & 1 & 0.050 \\
\hline
\end{tabular}

The next stage assesses the priorities of each actor considered with respect to one of the scenarios. The analysis is based on the relative strength and influence of each actor in shaping the priorities. One approach is to consider their influence with respect to the upper level (Level 1) in the hierarchy that concerns the different prevailing conditions as in Figure 2a. If the case of large number of players is considered, then the importance of ADS is medium, whereas ADQ is very high, and ADI and ADR high. The task to assign weights (importance) to the different decision-makers of the group is often a difficult one. We propose a simple and fair method, where the weights of the members are judged by the other members of the group (Ishizaka \& Labib, 2011).

The next step is concerned with finding the priorities of the various actors under each of the four conditions. This is shown in Table 2.

Table 2. Priorities of actors under each condition

\begin{tabular}{|c|c|c|c|c|c|}
\hline \multirow[b]{2}{*}{ Conditions: } & & \multirow[b]{2}{*}{ ADQ } & \multicolumn{3}{|c|}{ Actors (Stakeholders) } \\
\hline & & & ADR & ADS & ADI \\
\hline \multirow{2}{*}{$\begin{array}{l}\text { Economic } \\
\text { Conditions: }\end{array}$} & Recession & $\mathrm{VH}$ & $\mathrm{VH}$ & $\mathrm{M}$ & $\mathrm{M}$ \\
\hline & Growth & $\mathrm{M}$ & M & $\mathrm{VH}$ & $\mathrm{VH}$ \\
\hline \multirow{2}{*}{$\begin{array}{l}\text { Competitive } \\
\text { Environment: }\end{array}$} & Large Number of players & $\mathrm{VH}$ & $\mathrm{H}$ & M & $\mathrm{H}$ \\
\hline & Few Players & M & M & VH & M \\
\hline
\end{tabular}

In assessing, for example, the priorities of the actors with respect to a 'recession' and 'growth', the following comparison matrices are obtained as shown in Tables $3 \mathrm{~A}$ and $3 \mathrm{~B}$.

These results correlate with Table 2, where in the 'recession' row, ADQ and ADR have very high (VH) priority, and followed by both ADS and ADI, who score medium (M) whereas in 'growth' economic conditions, both ADS and ADI score $\mathrm{VH}$, and ADQ and ADR score M. Again, here we emphasise that the aim of this exercise is to present a methodology and a framework rather than a rigid model and hence one can vary the importance of actors by performing sensitivity analysis ('what-if') and the model will dynamically alter the importance of alternatives as we will see later on. 
Table $3 A$

Priorities of actor's level (Level 2) with respect to condition 3 (recession) in Level 1.

\begin{tabular}{llllll}
\hline $\begin{array}{l}\text { With respect to: } \\
\begin{array}{l}\text { Condition 3: } \\
\text { Recession }\end{array}\end{array}$ & $\boldsymbol{A D Q}$ & $\boldsymbol{A D R}$ & ADS & ADI & $\begin{array}{l}\text { Global Priority of } \\
\text { actors with respect to } \\
\text { Recession }\end{array}$ \\
\hline ADQ & & & & & \\
ADR & 1 & 1 & 6 & 6 & 0.429 \\
ADS & 1 & 1 & 6 & 6 & 0.429 \\
ADI & $1 / 6$ & $1 / 6$ & 1 & 1 & 0.071 \\
& $1 / 6$ & $1 / 6$ & 1 & 1 & 0.071 \\
\hline
\end{tabular}

Table $3 B$

Priorities of actor's level (Level 2) with respect to condition 3 (growth) in Level 1.

\begin{tabular}{llllll}
\hline $\begin{array}{l}\text { With respect to: } \\
\begin{array}{l}\text { Condition 3: } \\
\text { Growth }\end{array}\end{array}$ & $\boldsymbol{A D Q}$ & $\boldsymbol{A D R}$ & ADS & ADI & $\begin{array}{l}\text { Global Priority of } \\
\text { actors with respect to } \\
\text { Growth }\end{array}$ \\
\hline ADQ & 1 & 1 & $1 / 6$ & $1 / 6$ & 0.071 \\
ADR & 1 & 1 & $1 / 6$ & $1 / 6$ & 0.071 \\
ADS & 6 & 6 & 1 & 1 & 0.429 \\
ADI & 6 & 6 & 1 & 1 & 0.429 \\
\hline
\end{tabular}

Continuing on in the same fashion, the priorities of each objective under each condition are derived, as shown in Table 4.

Table 4. Local priorities of level 2 relative to level 1.

\begin{tabular}{lcccc}
\hline & \multicolumn{2}{c}{ Economic Conditions: } & \multicolumn{2}{c}{ Competitive Environment: } \\
& Recession & Growth & $\begin{array}{c}\text { Large Number } \\
\text { of players }\end{array}$ & Few Players \\
\hline ADQ & 0.429 & 0.071 & 0.535 & 0.167 \\
ADR & 0.429 & 0.071 & 0.196 & 0.167 \\
ADS & 0.071 & 0.429 & 0.073 & 0.500 \\
ADI & 0.071 & 0.429 & 0.196 & 0.167 \\
\hline
\end{tabular}

Note that the summation down each column must equal unity. The results demonstrate, for example, that the importance of the ADQ is significant during recession economic conditions and in the existence of large number of players as a competitive environment whereas the importance of ADS is significant in a few players situation and in growth economic conditions. Again this correlates with the data given in Table 2 . 
To derive the global priorities of the actors (i.e. how important these actors are to the overall goal and not just to each scenario), one must weight their relative (local) priorities (Table 4) by the priorities (likelihood) of the scenarios themselves (Table 1); this yields a vector (Table 5), which should also add to unity.

Table 5. Global priorities of actors.

\begin{tabular}{cc}
\hline Actors & Priorities \\
\hline $\boldsymbol{A D Q}$ & 0.44571 \\
ADR & 0.29313 \\
ADS & 0.11123 \\
ADI & 0.14993 \\
\hline
\end{tabular}

When dealing with different actors, if no consensus is reached, then a geometric mean can be used as suggested by Saaty (1980) to average the judgements. This completes the prioritisation of the first two levels, namely that of the scenarios and the actors.

The actors' objectives are to increase: accessibility and flexibility, research ranking, impact of research and knowledge transfer, student satisfaction and HEI reputation, as well as maximise efficient resource utilisation. For the sake of brevity, the judgements of different actors when considering the scenario of 'large number of players' are presented in Table 6. The judgements for these assessments were carried out by asking each of the actors to complete pair-wise comparisons with respect to their preferred objectives under every scenario.

Table 6. Local assessment of different actors' objectives with respect to the scenario of large number of players

\begin{tabular}{|c|c|c|c|c|c|c|}
\hline $\begin{array}{l}\text { With } \\
\text { respect to: } \\
\text { Large } \\
\text { number of } \\
\text { players }\end{array}$ & $\begin{array}{c}\text { accessibility } \\
\text { and } \\
\text { flexibility }\end{array}$ & $\begin{array}{c}\text { research } \\
\text { ranking }\end{array}$ & $\begin{array}{l}\text { impact of } \\
\text { research and } \\
\text { knowledge } \\
\text { transfer }\end{array}$ & $\begin{array}{c}\text { students } \\
\text { satisfaction }\end{array}$ & reputation & $\begin{array}{l}\text { efficient } \\
\text { resource } \\
\text { utilisation }\end{array}$ \\
\hline ADQ & 0.364 & 0.024 & 0.047 & 0.104 & 0.353 & 0.108 \\
\hline ADR & 0.058 & 0.268 & 0.105 & 0.268 & 0.268 & 0.033 \\
\hline ADS & 0.248 & 0.195 & 0.071 & 0.204 & 0.185 & 0.097 \\
\hline ADI & 0.049 & 0.081 & 0.139 & 0.248 & 0.451 & 0.032 \\
\hline
\end{tabular}

Note that the priority figures of each actor in Table 6 are in the form of decimals, and their summation across the rows adds up to unity. As shown in Table 6, due to his/her concern to maximise student numbers, the ADS prioritises his/her objectives to increase student satisfaction and maximise accessibility and flexibility, while the ADI prefers to increase reputation with some emphasis on student satisfaction and impact of research and knowledge transfer. The ADRs, major concern is research ranking, reputation and student satisfaction. The ADQs major concerns are accessibility and flexibility, and reputation.

To proceed to the third of the objectives and the last level of the relative attractiveness of alternative strategic investment options, we start by identifying areas that we need to prioritise with respect to each objective and then find the local priorities of the strategic options with respect to each objective. In order to minimise space, the detailed comparison matrices will not be presented but a summary of how alternatives are prioritised globally is shown in Figure 4 below. 


\title{
Global priorities of alternative strategic investments
}

\author{
Synthesis with respect to: \\ Goal: HE Strategy \\ Overall Inconsistency $=0.05$
}

Human Resources Development Marketing \&. Promotion

Management Information and Processes

Facilities 'learning space"

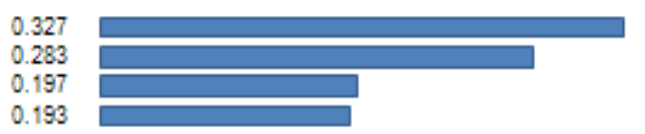

Figure 4. Global priorities of alternative strategic investments.

\section{RESULTS OF SENSITIVITY ANALYSIS}

The results of sensitivity analysis can be shown in Figures 5 and 6 , where the criteria are depicted as columns in Figure 5. For example, we show the scenario where recession is more likely than growth, and with a large number of players more likely than few numbers of players. Figure 5 also shows the performance of each of the objectives with respect to each of the scenarios in the high recession scenario: Human Resources > Marketing > Management Information > Facilities 'learning space' (where ' $>$ ' signifies 'more important than'), whereas in the scenario of large number of players: Marketing > Human Resources > Facilities 'learning space' > Management Information. Hence, in terms of global (overall) priorities: Human Resources > Marketing > Management Information > Facilities 'learning space'. 


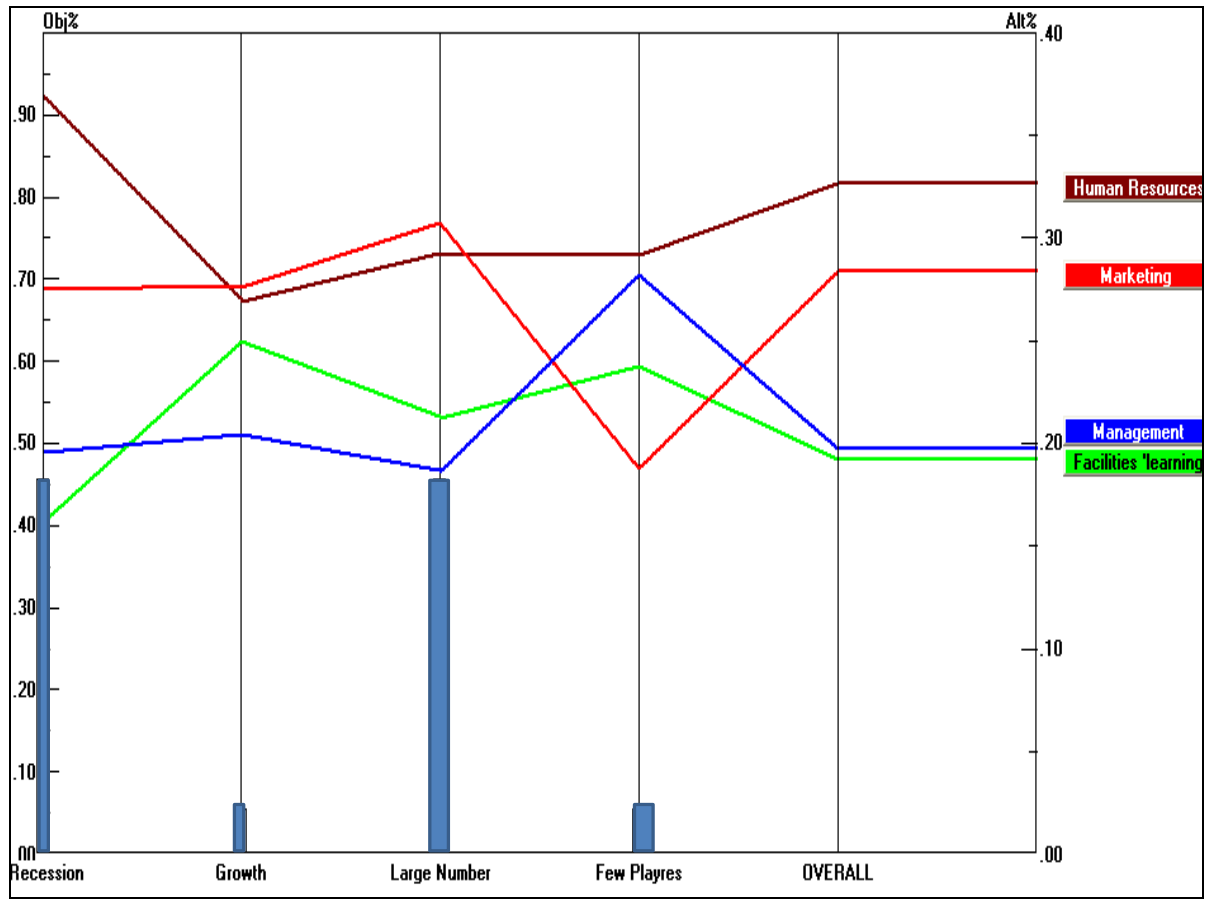

Figure 5. Sensitivity Analysis: alternative strategic investments

with respect to different scenarios.

But what happens if growth becomes more likely than recession with a large number of players? The impact on the rank order of global investment priorities (shown at the right of Figure 6) can be noticed when the column growth is increasing as well as the column at large numbers of players. So at the 'Overall Column' at the very right hand side, the importance of the alternatives Marketing will increase, followed by Human Resources, followed by Facilities, and finally Management Information, and so on. This 'what-if' analysis is very powerful as it can help us to predict the importance of alternative strategic investments in changing environments that will affect the importance of different scenarios. 


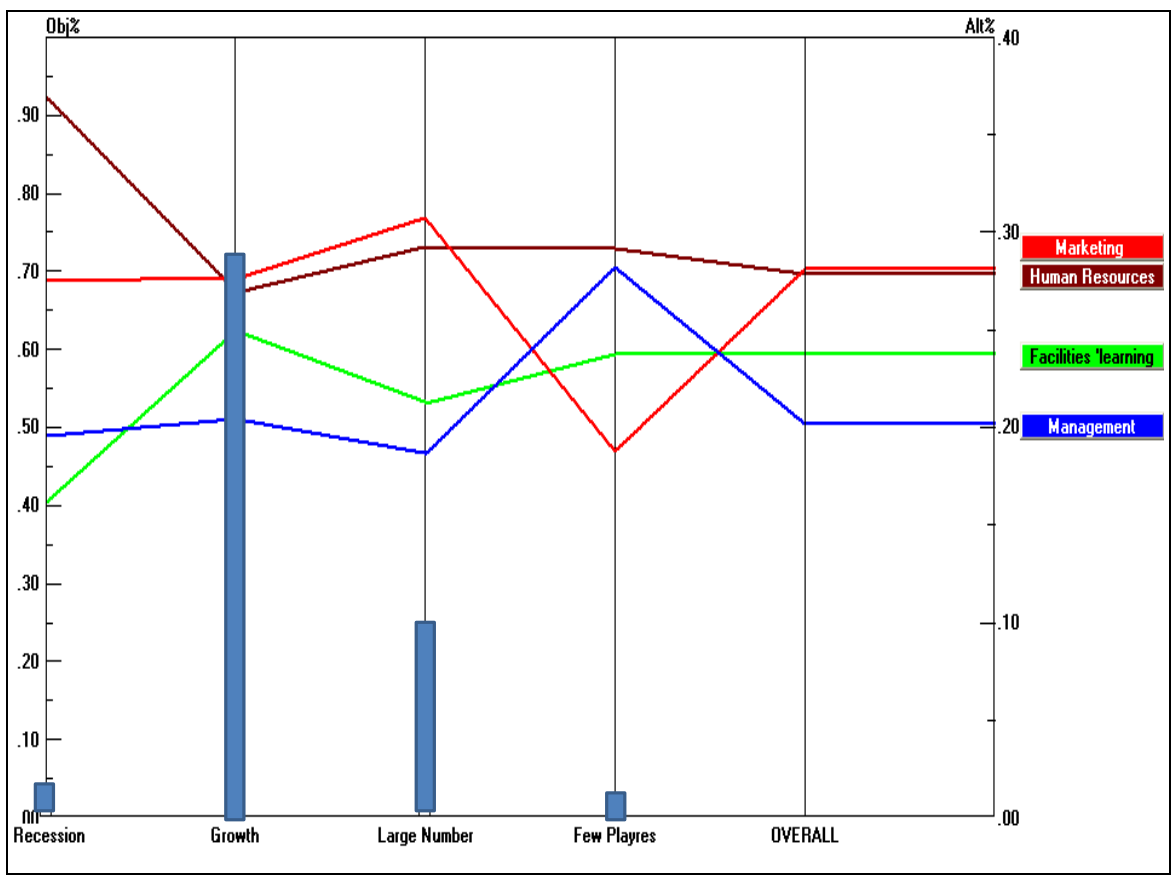

Figure 6: Sensitivity analysis: Alternative strategic investments with respect to different scenarios.

'What if' Growth increases as well as Large Number of Players? 
RESOURCE ALLOCATION (THE KNAPSACK METHOD)

Once preferred alternative strategic investments have been established, the issue then becomes one of identifying how the available resources can best be utilised across the alternatives to produce the maximum benefit for the organisation, When we have a measurable quantity of resource to be allocated to a set of alternative strategies, we need to maximise some objective subject to a constraint on the total resources available.

To allocate a resource we need to examine what is needed and how it should be allocated. Therefore, we need to analyse alternatives in terms of how strongly they fulfil the objectives and also in terms of what it would cost to implement these alternatives. It may be that two alternatives together may accrue a greater benefit than a single one.

The resource allocation approach is based on the Knapsack method, where the outputs of the AHP, in the form of global priorities of alternatives, are used here as inputs to the method. The second input to the method is the total resources available as well as the resources required for implementation of each optional strategy (alternative). Knapsack is a combinatorial optimisation method to distribute limited resources to different activities.

This concept is formalised mathematically in the form of the Knapsack method as shown below:

$\operatorname{maximise} \sum_{i}^{n} p r_{i} \cdot s_{i}$

subject to : $\sum_{i}^{n} c_{i j} \cdot s_{i} \leq \mathrm{F}_{\mathrm{j}}$

where:

$$
\begin{aligned}
& p r_{i} \text { and } c_{i j} \geq 0 \\
& s_{i} \in\{0,1\} \\
& s_{i} \quad=1 \text { if alternative } i \text { is selected } \\
& \quad=0 \text { otherwise } \\
& i=1, \ldots . ., \mathrm{n} \\
& j=1, \ldots ., \mathrm{m}
\end{aligned}
$$


$F_{j} \quad$ is the available amount of the $j^{\text {th }}$ resource at the institution (Funds available).

$\mathrm{s}_{i} \quad$ is alternative strategy $i$.

$p r_{i} \quad$ is priority of $i^{\text {th }}$ alternative obtained through solving the AHP model.

$c_{i j} \quad$ is the expected amount of resource required by the $i^{\text {th }}$ alternative.

There are $n$ alternatives, which require $m$ resources.

The objective is to find the optimal assignment of resources to strategic alternatives so as to maximise the sum of resource utilisation and utility (satisfaction).

So, given that the global priorities of alternative strategic investments from the AHP model as per figure 4 are shown in table 7: 
Table 7: Global priorities of alternative strategic investments from the AHP model as per Figure 4

\begin{tabular}{|l|l|}
\hline \multicolumn{1}{|c|}{ Alternative strategic investments } & \multicolumn{1}{|c|}{ Global priorities } \\
\hline Human Resources Development & 0.327 \\
\hline Marketing \& Promotion & 0.283 \\
\hline Management Information and Processes & 0.197 \\
\hline Facilities 'learning space' & 0.193 \\
\hline TOTAL: & 1 \\
\hline
\end{tabular}

Also given an inventory of resources available (i.e. available budget to invest) as shown in Table 8 below:

Table 8: Resources available (i.e. available budget to invest)

\begin{tabular}{|l|l|l|l|l|}
\hline & Money (£) & $\begin{array}{l}\text { Personnel } \\
\text { (No. of staff) }\end{array}$ & Time (days) & $\begin{array}{l}\text { Equipment } \\
\text { (units) }\end{array}$ \\
\hline Value: & 100,000 & 3 & 90 & 5 \\
\hline
\end{tabular}

Finally, given resources required for implementation of each optional strategy (alternative) as shown in Table 9 below: 
Table 9: Resource requirements

\begin{tabular}{|l|l|l|l|l|}
\hline & Money (£) & $\begin{array}{l}\text { Personnel } \\
\text { (No. of staff) }\end{array}$ & Time (days) & $\begin{array}{l}\text { Equipment } \\
\text { (units) }\end{array}$ \\
\hline $\begin{array}{l}\text { A: } \\
\text { Management } \\
\text { Information } \\
\text { Systems and } \\
\text { Processes } \\
\text { (IS) }\end{array}$ & 10,000 & 1 & 1 & 0 \\
\hline $\begin{array}{l}\text { B:Marketing } \\
\text { \& Promotion } \\
\text { (Mrktg) }\end{array}$ & 15,000 & 1 & 10 & 0 \\
\hline $\begin{array}{l}\text { C: Facilities } \\
\text { 'learning } \\
\text { space' (Faclts) }\end{array}$ & 70,000 & 2 & 50 & 3 \\
\hline $\begin{array}{l}\text { D: Human } \\
\text { resources } \\
\text { development } \\
\text { (HRD) }\end{array}$ & 50,000 & 3 & 30 & 2 \\
\hline
\end{tabular}

Now, since we need to maximise utility one starts by choosing the strategy option with the highest priority (utility), which according to Table 7 is 'Human Resource Development' (HRD). Taking into consideration resources required for implementation of HRD based on the information provided in Table 9, and the total available inventory of resources shown in Table 8, then one can compute resources available after implementation of strategy option HRD as shown in Table 10 below: 
Table 10: Resources available after implementation of D: HRD Strategy

\begin{tabular}{|l|l|l|l|l|}
\hline & Money (£) & $\begin{array}{l}\text { Personnel } \\
\text { (No. of staff) }\end{array}$ & Time (days) & $\begin{array}{l}\text { Equipment } \\
\text { (units) }\end{array}$ \\
\hline Value: & 50,000 & 0 & 60 & 3 \\
\hline
\end{tabular}

Values in Table 10 are based on information provided in tables 8 and 9 and are computed as follows:

Money $=100,000-50,000=50,000$

Personnel $=3-3=0$

Time $=90-30=60$

Equipment $=5-2=3$

With these amount of resources one cannot implement any other optional strategy as none of them can be implemented based on the resource requirements for each strategy outlined in Table 9.

Alternatively, one can decide instead to implement strategies 'A: IS' plus 'B: Mrktg' the utility gained will be 0.48 (which is equal to adding their global priorities $0.197+0.283$ ), which is a higher utility than just choosing the best optional strategy 'D: HRD' which has a utility (priority) of just 0.327 .

Now, resources available after implementation of strategies 'A: IS' plus 'B: Mrktg' are shown in Table 11 below:

Table 11: Resources available after implementation of Strategies 'A: IS' plus 'B: Mrktg'

\begin{tabular}{|l|l|l|l|l|}
\hline & Money (£) & $\begin{array}{l}\text { Personnel } \\
\text { (No. of staff) }\end{array}$ & Time (days) & $\begin{array}{l}\text { Equipment } \\
\text { (units) }\end{array}$ \\
\hline Value: & 75,000 & 1 & 79 & 5 \\
\hline
\end{tabular}

Values in Table 11 are based on information provided in tables 8 and 9 and are computed as follows: 
Money $=100,000-(10,000+15,000)=75,000$

Personnel $=3-(1+1)=1$

Time $=90-(1+10)=79$

Equipment $=5-(0+0)=5$

This iteration illustrates that although the best option based on AHP is desirable, but given the resources available and the resource requirements, we gain more utility (satisfaction) by implementing the second and third best options instead. This iteration is based on the dynamic programming approach.

The whole process can be summarised as shown in Figure 7 below.

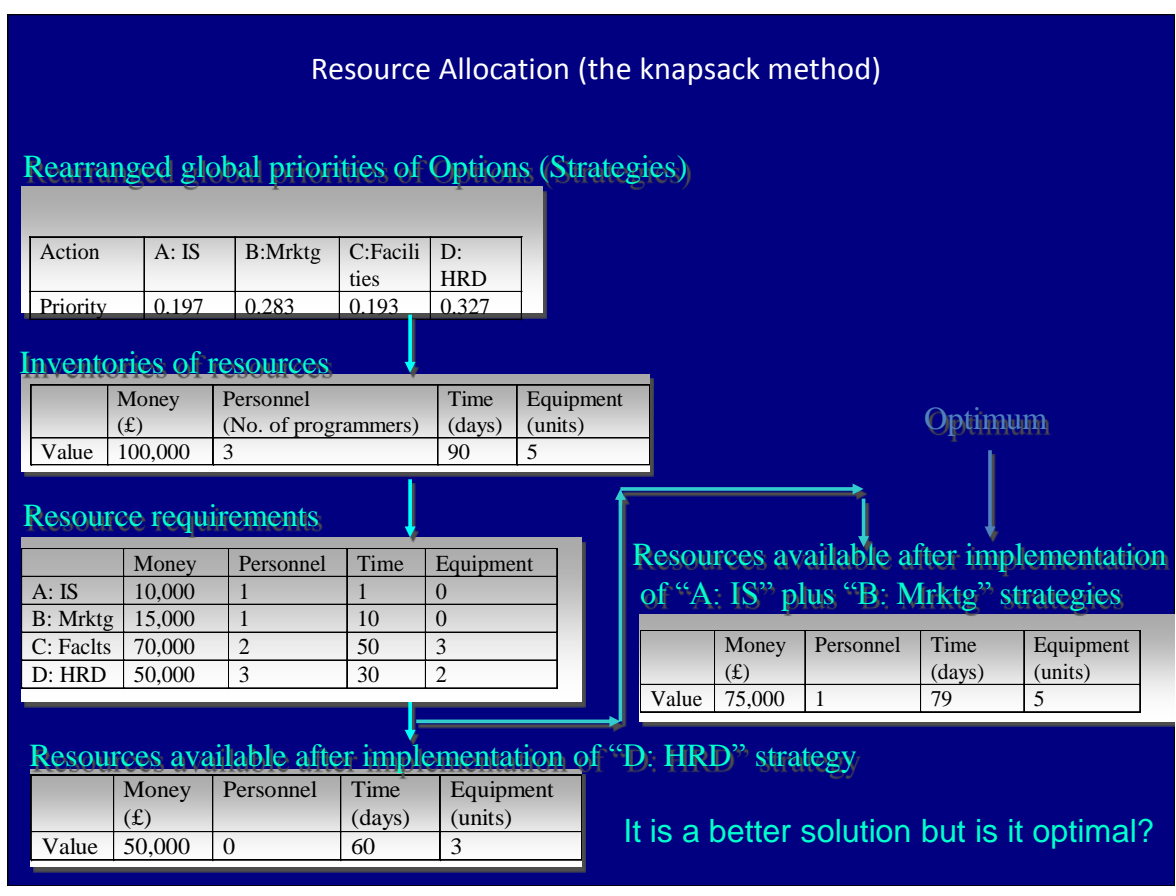

Figure 7: The Knapsack method applied to optimise resources

\section{CONCLUSION}

In this paper, we described a novel approach for classification of one of the most critical issues in HE - strategic investment. We focused on the importance of strategic decision-making in prioritising particular strategic objectives. We applied AHP in a manner intended to achieve more dynamism in strategic planning analysis and to provoke more predictive thought by accommodating aspects of the external business environment to modify the relative power positions of the members of the decision-making unit in $\mathrm{HE}$, and thus the relative importance of the objectives. The 
model, once built, can then be subjected to sensitivity analysis, allowing the decision-makers to explore "what-if" scenarios, in a way which is rarely possible with strategic analysis based primarily on past financial performance. The outputs of the AHP method were then used as inputs to a resource allocation method where we demonstrated how to optimise available resources. The issue of time dependency, particularly in the budget allocation /Knap-sack method is of interest, as the assumed timescale for strategic decisions in the AHP process may be different from (probably longer than) the budget timescale. For example: AHP 5 years, Budget 1 or 2 years. This raises the question of second/third budget rounds, and the potential for sub-optimisation by only considering the first round. This is beyond the scope of the current work, but is an area that needs further research.

Although the total number of pair-wise comparisons were 204 per actor, this process of performing pair-wise comparison has served to refine the judgements, rather than depending on just a few judgements which may be subject to errors. In other words, if one is making an experiment by taking readings and repeating the process many times, this will produce better results, rather than relying on just a few measures where a single error would be significant. In order to monitor the quality of the judgements, the consistency measure was used as a feedback mechanism and when high inconsistency was observed the actor was asked to double-check that particular judgement.

In this paper we have used an example of a business school to identify focus for its strategic investment, but the same approach could easily be applied to other settings, for example the entire HEI strategic plan, or indeed smaller units, such as other individual faculties, or service centres such as Information Services or Marketing. The method is also flexible and generic, in that it can consider other conditions, actors, objectives and strategic investment options.

The whole method attempts to 'systematise' the decision making process and to model a complex problem that is concerned with HEI strategy formulation. Nevertheless, this does not mean that we ignore issues related to 'ownership', and involvement of staff, when major initiatives are being planned as outlined by Newton (2003). What we have proposed in this paper is the beginning of such a process in terms of identifying areas of priorities rather than the end result of implementation of a strategy per se. This is based on the premise that strategies neither implement themselves, nor lead automatically to improvement. The proposed model in this paper is sufficiently general to allow the incorporation of a range of influential environmental factors, key stakeholders, and objectives. It is also specific enough in that it can help to prioritise strategic options and optimise allocation of scarce resources.

\section{REFERENCES}

1. Cheng, E.W.L., Li, H., Utility consistency measure in the analytic hierarchy process, Construction Innovation, 3:231-247, 2003.

2. EPSRC. (2004). A review undertaken on behalf of the Engineering and Physical Sciences Research Council (EPSRC), Economic and Social Research Council (ESRC) and Operational Research Society (ORS), Engineering and Physical Science Research Council, Swindon, UK.

3. Gladstone-Millar, C., Labib, A., Tonge, R., Smith, D., An Operational Research Technique for the Formulation of Higher Education Institutional Strategy and Future Directions, Edited by: Bell, G.A., Warwick, J., Galbraith, P., Higher Education Management and Operational Research: Demonstrating New 
Practices and Metaphors, Publisher: SENSE PUBLISHERS B.V., Rotterdam, The Netherlands, 2012.

4. HEFCE. (2000). Report 00/24: Strategic planning in higher education: A guide for heads of institutions, senior managers, and members of governing bodies, Higher Education Funding Council for England, London, UK.

5. Ishizaka, A., \& Labib, A. (2009). Analytic hierarchy process and expert choice: Benefits and limitations. OR Insight, 22(4), 201-220.

6. Ishizaka, A., \& Labib A. (2011). Selection of new production facilities with the group analytic hierarchy process ordering method. Expert Systems with Applications, 38, 7317-7325.

7. Jones, P., and Lewis, J., Implementing a Strategy for Collective Change in Higher Education, Studies in Higher Education Volume 16, No. 1, 1991.

8. Kumar, S., \& Vaidya, O. (2006). Analytic hierarchy process: An overview of applications. European Journal of Operational Research, 169(1), 1-29.

9. Labib, A.W., O’Connor, R.F., \& Williams, G.B. (1997). Deriving a maintenance strategy through the application of a multiple criteria decision making methodology. In G. Fandel \& T. Gal (Eds.). Lecture notes in economics and mathematical systems; No. 448 (pp. 481-490). Springer-Verlag, Germany.

10. Newton, J., Implementing an Institution-wide Learning and Teaching Strategy: lessons in managing change, Studies in Higher Education Volume 28, No. 4, October 2003.

11. Omkarprasad, V., \& Sushil, K. (2006). Analytic hierarchy process: an overview of applications. European Journal of Operational Research, 169(1), 1-29.

12. Saaty, T. L. (1977). A scaling method for priorities in hierarchical structures. Journal of Mathematical Psychology, 15 (1), 57-68.

13. Saaty, T. L. (1980). The analytic hierarchy process. New York, NY: McGrawHill International.

14. Saaty, T. L. (1994). Fundamentals of decision making and priority theory with the AHP. Pittsburgh, PA: RWS Publications.

15. Vassoula, V., Labib, A. W. \& Roberts, M. (2006). A decision model for junction improvement schemes. Proceedings of the Institution of Civil Engineers Transport, 159(TR3), 127-134.

Number Of Words: 6,606 